\title{
A Novel Extension Decision-Making Method for Selecting Solar Power Systems
}

\author{
Meng-Hui Wang \\ Department of Electrical Engineering, National Chin-Yi University of Technology, Taichung 41110, Taiwan \\ Correspondence should be addressed to Meng-Hui Wang; wangmh@ncut.edu.tw
}

Received 29 October 2012; Accepted 16 January 2013

Academic Editor: Tapas Mallick

Copyright (C) 2013 Meng-Hui Wang. This is an open access article distributed under the Creative Commons Attribution License, which permits unrestricted use, distribution, and reproduction in any medium, provided the original work is properly cited.

\begin{abstract}
Due to the complex parameters of a solar power system, the designer not only must think about the load demand but also needs to consider the price, weight, and annual power generating capacity (APGC) and maximum power of the solar system. It is an important task to find the optimal solar power system with many parameters. Therefore, this paper presents a novel decisionmaking method based on the extension theory; we call it extension decision-making method (EDMM). Using the EDMM can make it quick to select the optimal solar power system. The paper proposed this method not only to provide a useful estimated tool for the solar system engineers but also to supply the important reference with the installation of solar systems to the consumer.
\end{abstract}

\section{Introduction}

In recent years, global warming caused the sea levels rising. As a result, the loss of coastal wetlands causes the erosion of the coastline and the continued flooding in the low-lying area. Regional climate changes also caused serious striking against the environmental ecology and agriculture. The greenhouse effect and global warming are becoming increasingly apparent. In the past two decades, the economy has grown rapidly in Taiwan, and it made the energy requirement increase greatly. However, there is an extreme shortage of energy resources in Taiwan. Also, 99 percent of the energy must rely on import from the foreign countries. Facing the fossil-fuel shortage crisis, Taiwan is actively opening up the renewable energy at present. The solar energy is one of the renewable energy resources with the highest acceptance in Taiwan.

Because Taiwan is located in subtropics, the temperature and the sunlight suit to develop the solar power system. Solar power system has high potential. When the solar power system operates, it neither produces the air pollution nor generates a large number of $\mathrm{CO}_{2}$. Therefore, this system is very helpful to reduce the global warming and the demand of fossil energy. The solar power system is also a clean and safe power supply system for businesses and families $[1,2]$.

The semiconductor industry fairly matures in Taiwan. The electronic power technology development is stepping into a new stage. There is a quite good basis on manufacturing technology and R\&D manpower. By the global photovoltaic (PV) industry growth trends, it is high competition to develop the solar power system in Taiwan. According to the industry statistics until 2007, there are more than 70 solar power system companies and solar power system output is $430 \mathrm{MW}$ which is the fourth in the world. The PVs industry production is worth 53.5 billion dollars. It is beneficial to save the energy and reduce $\mathrm{CO}_{2}$ and the industrial development. In part of the solar development, the single crystal silicon solar cell efficiency has reached $21 \%$, and the polysilicon solar cell efficiency is up to $18.5 \%$. The high efficient design and the packaging technologies in the PV module technology have been established. In 2012, we expect to be completed to install 20,000 families, and the capacity of $60 \mathrm{MW}$ installations. The solar energy system can generate 7,200 million kWh per year. It promotes the development of the domestic PV industry, creates the domestic markets, and develops the industries.

When the solar power system is installed, it needs to consider the loading demand and the installing area. For the user, it is important to consider with the recovered cost, APGC, and the total weight of solar power system [3]. Confronting the variety of solar power system in the market, the solar system is an important task of how to select the best option from the specifications provided. Therefore, this 
paper presents a novel decision-making method based on the extension theory [4-6]; we call it extension decision-making method (EDMM). First, according to the specifications of PV cell provided by the manufacturer, this paper uses the commercial software to simulate every solar power system and to compute the APGC of solar system. Then, this paper uses the proposed EDMM to count the evaluation index of every system. Using the evaluation index can make it easy to select the optimal system. This proposed method not only provides the system engineers with as a very useful assessment tool, but also supplies the users with the important reference when setting a solar power system. In addition, this paper proposes the method which can be added or subtracted to the characteristic and weight by the user's requirement. We hope that the proposed method will lead to further investigation for other renewable energy systems.

\section{Review of Extension Theory}

In the standard set, an element either belongs to or not belongs; so, the range of the standard set is $\{0,1\}$, which can be used to solve a two-valued problem. In contrast to the standard set, the fuzzy set allows the description of concepts in which the boundary is not explicit. It concerns not only whether an element belongs to the set but also to what degree it belongs to the set. The range of a fuzzy set is $[0,1]$. The extension set extends the fuzzy set from $[0,1]$ to $(-\infty, \infty)$. As a result, it allows us to define a set that includes any data in the domain. Extension theory tries to solve the incompatibility or contradiction problems by the transformation of the matter element $[7,8]$. The comparisons of the standard sets, fuzzy sets, and extension sets are shown in Table 1. Some definitions of extension theory are introduced in the next section.

\subsection{Matter-Element Theory}

2.1.1. Definition of Matter-Element. Defining the name of matter as $N$, the characteristics of the matter as $c$, and the value of $c$ as $v$, a matter-element in extension theory can be described as follows:

$$
R=(N, c, v)
$$

where $N, c$, and $v$ were called the three fundamental elements of the matter-element. If the value of the characteristic has a classical domain or a range, then we define the matterelement for the classical domain as follows:

$$
R=(N, c, v)=\left(N, c,\left\langle v^{L}, v^{U}\right\rangle\right)
$$

where $v^{L}$ and $v^{U}$ are the lower bound and upper bound of a classical domain.

2.1.2. Multidimensional Matter-Element. Assuming $R=$ $(N, C, V)$ to be a multidimensional matter-element, $C=$ $\left[c_{1}, c_{2}, \ldots, c_{n}\right]$ a characteristic vector, and $V=\left[v_{1}, v_{2}, \ldots, v_{n}\right]$ a value vector of $C$, then a multidimensional matter-element is defined as

$$
R=\left[\begin{array}{c}
N, c_{1}, v_{1} \\
c_{2}, v_{2} \\
\vdots \\
c_{n}, v_{n}
\end{array}\right]=\left[\begin{array}{c}
R_{1} \\
R_{2} \\
\vdots \\
R_{n}
\end{array}\right]
$$

where $R_{i}=\left(N, c_{i}, v_{i}\right)(i=1,2, \ldots, n)$ is defined as the submatter-element of $R$.

\subsection{Extension Set Theory}

2.2.1. Definition of Extension Set. Let $U$ be the universe of discourse; then, an extension set $\widetilde{A}$ on $U$ is defined as a set of ordered pairs as follows:

$$
\widetilde{A}=\{(v, y) \mid v \in U, y=K(v) \in(-\infty, \infty)\},
$$

where $y=K(x)$ is called the correlation function for extension set $\widetilde{A}$. The $K(x)$ maps each element of $U$ to a membership grade between $-\infty$ and $\infty$. The higher degree and the more elements belong to the set. In a special condition, when $0 \leq K(x) \leq 1$, it corresponds to a normal fuzzy set. $K(x) \leq-1$ implies that the element $x$ has no chance to belong to the set. When $-1<K(x)<0$, it is called an extension domain, which means that the element $x$ still has a chance to become part of the set.

2.2.2. Definition of Correlation Function. The correlation functions have many forms dependent on application. If we set $V_{o}=\langle a, b\rangle$ and $V=\langle c, d\rangle$ being two intervals in the real number field, and $V_{o} \in V$, then the correlation function in the extension theory can be defined as follows:

$$
K(v)=\frac{\rho\left(v, V_{o}\right)}{D\left(v, V_{o}, V\right)},
$$

where

$$
\begin{gathered}
D\left(v, V_{o}, V\right)= \begin{cases}\rho(v, V)-\rho\left(v, V_{o}\right), & v \notin V_{o}, \\
-1, & v \in V_{o},\end{cases} \\
\rho\left(v, V_{o}\right)=\left|x-\frac{a+b}{2}\right|-\frac{b-a}{2}, \\
\rho(v, V)=\left|x-\frac{c+d}{2}\right|-\frac{d-c}{2} .
\end{gathered}
$$

The correlation function can be used to calculate the membership grade between $x$ and $V_{o}$ as shown in Figure 1 .

2.3. Decision-Making Method for Solar Power System. Using the decision-making method for the solar power systems, it must have a software suit to simulate APGC, the maximum power, and the current of the solar power systems. Then, we can use the characteristics of solar power system to build the matter-element model of solar systems and to calculate the estimated index for selecting rank. 
TABLE 1: Three different sorts of mathematical sets.

\begin{tabular}{lccc}
\hline Compared item & Standard set & Fuzzy set & Extension set \\
Research objects & Data variables & Linguistic variables & Contradictory problems \\
Model & Mathematics model & Fuzzy mathematics model & Matter-element model \\
Descriptive function & Transfer function & Membership function & Correlation function \\
Descriptive property & Precision & Ambiguity & Extension \\
Range of set & $C_{A}(x) \in(0,1)$ & $\mu_{A}(x) \in[0,1]$ & $K_{A}(x) \in(-\infty, \infty)$ \\
\hline
\end{tabular}

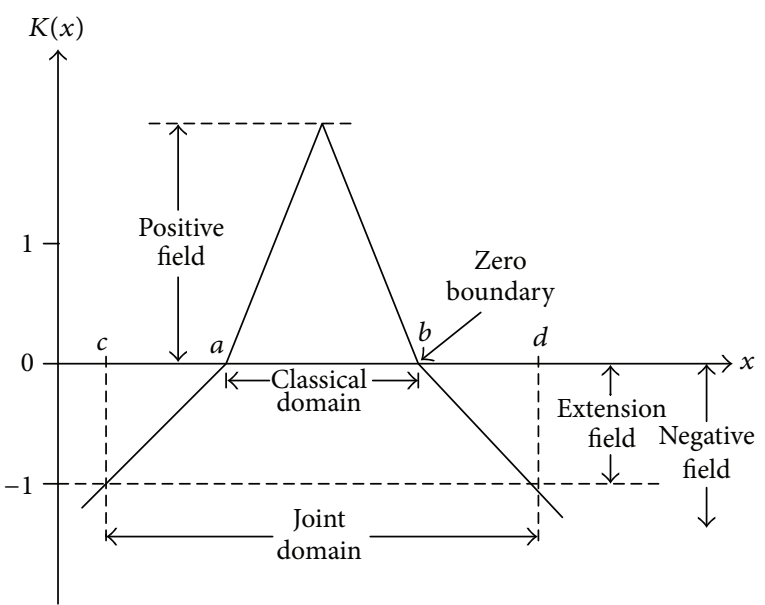

FIgURE 1: The proposed extended relation function.

2.4. Test Conditions. The paper is based on the simulated software to unify the location, area, the direction of harmonization, and the horizontal angle for the solar power system. It simulates all the conditions of each solar power system installed in the location of the latitude and longitude, respectively, $(24,9)$ and $(120,40)$, in Taichung. Then, it simulates the solar power system and the horizontal included angle is 23 degrees and the panel toward the south. The simulated total area of the solar power system is 50 square meters. There are established five groups of the matterelement model according to the characteristics which are the APGC, the maximum power, the maximum current, the total cost, and the total weight of the solar power systems.

The first three data statistics calculate from the commercial simulation software, the typical simulated results of the solar power system can be shown in Figures 2 and 3, there are easy to calculate the APCG, maximum power, and current of the tested solar system.

The two other data are provided from the producers of solar power systems. Table 2 shows the specification of different solar systems. Then, the paper uses the earlier 5 characteristics to create the matter-element model as shown in Table 3. Here, the A-class represents the best solar module. The opposite E-class represents the worst solar module. Table 3 shows that the $c 1$ is APGC, $c 2$ is the maximum power, $c 3$ is the total cost, $c 4$ is the maximum current, and $c 5$ is the total weight.

2.5. The Proposed Extension Decision-Making Method. This paper has been successfully using computer software to
TABLE 2: Specifications of the different PV modules.

\begin{tabular}{|c|c|c|c|c|c|}
\hline \multirow[b]{2}{*}{$\begin{array}{l}\text { PV } \\
\text { samples }\end{array}$} & \multicolumn{5}{|c|}{ Characteristics } \\
\hline & $\begin{array}{c}\text { APGC } \\
\text { (kwh/year) }\end{array}$ & $\begin{array}{c}\text { Max. } \\
\text { power } \\
(\mathrm{kw})\end{array}$ & $\begin{array}{c}\text { Cost } \\
\left(10^{3} \text { USD }\right)\end{array}$ & $\begin{array}{c}\text { Max. } \\
\text { current } \\
\text { (A) }\end{array}$ & $\begin{array}{c}\text { Weight } \\
\text { (kg) }\end{array}$ \\
\hline Module 1 & 4962 & 4.2 & 23.6 & 240 & 380 \\
\hline Module 2 & 4575 & 3.8 & 23.6 & 238 & 395 \\
\hline Module 3 & 11969 & 10.3 & 42.1 & 253 & 800 \\
\hline Module 4 & 3890 & 3.7 & 51.5 & 119 & 1030 \\
\hline Module 5 & 6998 & 6.2 & 30.1 & 174 & 644 \\
\hline Module 6 & 6629 & 5.6 & 24.8 & 330 & 608 \\
\hline Module 7 & 6685 & 6.0 & 27.7 & 341 & 608 \\
\hline Module 8 & 5251 & 4.3 & 44.1 & 288 & 662 \\
\hline Module 9 & 4528 & 4.1 & 40.8 & 131 & 836 \\
\hline Module 10 & 6833 & 6.2 & 26.8 & 363 & 886 \\
\hline Module 11 & 6286 & 5.1 & 52.3 & 220 & 420 \\
\hline Module 12 & 7255 & 6.3 & 29.7 & 178 & 570 \\
\hline Module 13 & 7858 & 6.7 & 29.3 & 186 & 532 \\
\hline Module 14 & 7812 & 6.3 & 30.9 & 356 & 600 \\
\hline Module 15 & 7915 & 6.2 & 32.7 & 356 & 601 \\
\hline Module 16 & 6543 & 5.7 & 32.2 & 324 & 672 \\
\hline Module 17 & 7284 & 6.4 & 23.5 & 127 & 812 \\
\hline Module 18 & 7415 & 5.5 & 30.7 & 332 & 550 \\
\hline Module 19 & 12614 & 10.8 & 47.3 & 257 & 800 \\
\hline Module 20 & 12297 & 10.5 & 42.4 & 255 & 800 \\
\hline Module 21 & 11094 & 9.5 & 49.0 & 172 & 1150 \\
\hline Module 22 & 5824 & 4.6 & 29.7 & 278 & 814 \\
\hline Module 23 & 4335 & 4.1 & 51.3 & 199 & 624 \\
\hline Module 24 & 7303 & 6.0 & 33.1 & 338 & 589 \\
\hline Module 25 & 3903 & 3.5 & 49.3 & 221 & 516 \\
\hline Module 26 & 8209 & 7.1 & 24.9 & 236 & 480 \\
\hline Module 27 & 4307 & 3.9 & 47.0 & 125 & 941 \\
\hline Module 28 & 6943 & 5.9 & 30.5 & 338 & 476 \\
\hline Module 29 & 10200 & 8.8 & 40.1 & 219 & 660 \\
\hline Module 30 & 2134 & 2.1 & 38.6 & 121 & 620 \\
\hline
\end{tabular}

implement the proposed method for the selection of solar power systems; the details of the proposed method are shown as follows. 
TABLE 3: Matter-element models of different classes.

\begin{tabular}{|c|c|c|c|c|}
\hline \multirow{4}{*}{$\begin{array}{l}\text { Classes } \\
\text { A-Class }\end{array}$} & \multicolumn{4}{|c|}{ Matter-element models } \\
\hline & \multirow{5}{*}{$R 1=$} & A & $c 1$ & $\langle 80,100\rangle$ \\
\hline & & & $c 2$ & $\langle 80,100\rangle$ \\
\hline & & & $c 3$ & $\langle 0,20\rangle$ \\
\hline & & & $c 4$ & $\langle 80,100\rangle$ \\
\hline & & & $c 5$ & $\langle 0,20\rangle$ \\
\hline \multirow{5}{*}{ B-Class } & \multirow{5}{*}{$R 2=\{$} & B & $c 1$ & $\langle 60,80\rangle$ \\
\hline & & & $c 2$ & $\langle 60,80\rangle$ \\
\hline & & & $c 3$ & $\langle 20,40\rangle$ \\
\hline & & & $c 4$ & $\langle 60,80\rangle$ \\
\hline & & & $c 5$ & $\langle 20,40\rangle$ \\
\hline \multirow{5}{*}{ C-Class } & \multirow{5}{*}{$R 3=\{$} & & $c 1$ & $\langle 40,60\rangle$ \\
\hline & & & $c 2$ & $\langle 40,60\rangle$ \\
\hline & & & $c 3$ & $\langle 40,60\rangle$ \\
\hline & & & $c 4$ & $\langle 40,60\rangle$ \\
\hline & & & $c 5$ & $\langle 40,60\rangle$ \\
\hline \multirow{5}{*}{ D-Class } & \multirow{5}{*}{$R 4=\{$} & $\mathrm{D}$ & $c 1$ & $\langle 20,40\rangle$ \\
\hline & & & $c 2$ & $\langle 20,40\rangle$ \\
\hline & & & $c 3$ & $\langle 60,80\rangle$ \\
\hline & & & $c 4$ & $\langle 20,40\rangle$ \\
\hline & & & $c 5$ & $\langle 60,80\rangle$ \\
\hline \multirow{5}{*}{ E-Class } & \multirow{5}{*}{$R 5=\{$} & $\mathrm{E}$ & $c 1$ & $\langle 0,20\rangle$ \\
\hline & & & $c 2$ & $\langle 0,20\rangle$ \\
\hline & & & $c 3$ & $\langle 80,100\rangle$ \\
\hline & & & $c 4$ & $\langle 0,20\rangle$ \\
\hline & & & $c 5$ & $\langle 80,100\rangle$ \\
\hline
\end{tabular}

Step 1. Normalize the values of the characteristics into an interval between 0 and 100 as in (7). This process will be beneficial for estimation of solar systems. Consider

$$
\begin{gathered}
V_{j}^{\text {new }}=\left(\frac{V_{j}^{\text {old }}-V_{\min }}{V_{\max }-V_{\min }}\right) \times 100, \\
V_{\max }=\max \left\{V_{j}\right\}, \\
V_{\min }=\min \left\{V_{j}\right\} .
\end{gathered}
$$

Step 2. Establish the matter-element model of every rank according to Table 3, where

$$
R_{i}=\left\{\begin{array}{rrr}
\text { class } & c 1 & v_{i 1} \\
& c 2 & v_{i 2} \\
c 3 & v_{i 3} \\
c 4 & v_{i 4} \\
c 5 & v_{i 5}
\end{array}\right\} .
$$

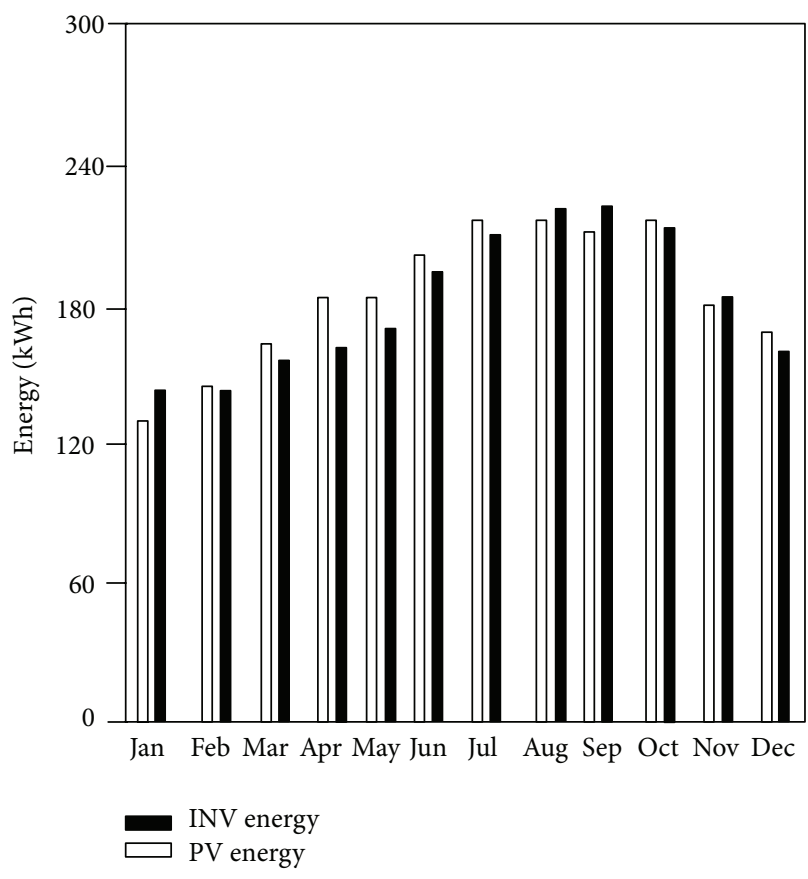

FIGURE 2: The typical APGC curves of the solar power system.

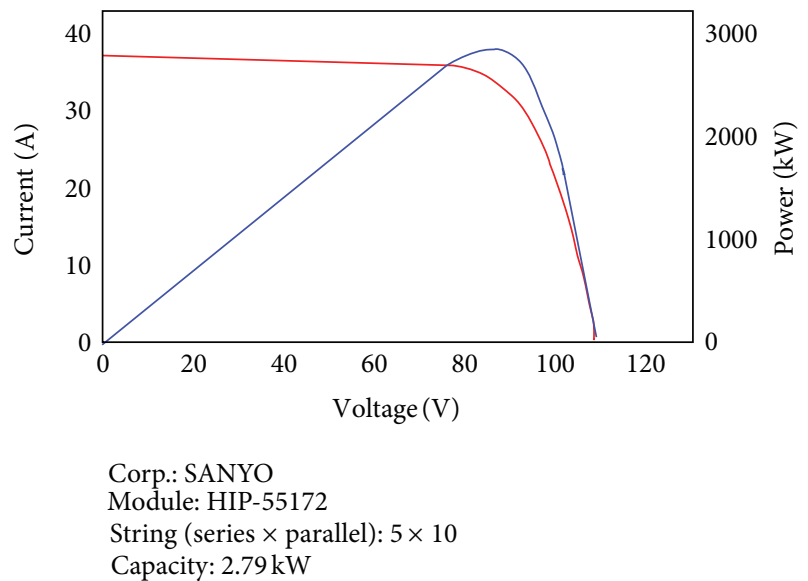

FIgURE 3: The typical maximum power and current curves of the solar power systems.

Step 3. Calculate the correlation index of every rank with the proposed extended correlation function as follows:

$$
K_{i j}= \begin{cases}-\rho\left(v_{i}, V_{i j}\right), & v_{i} \in V_{i j}, \\ \frac{\rho\left(v_{i}, V_{i j}\right)}{\rho\left(V_{i}, V_{p i}\right)-\rho\left(V_{i}, V_{i j}\right)}, & v_{i} \notin V_{i j}, \\ i=1,2, \ldots, 5 ; \quad j=1,2, \ldots, 5 .\end{cases}
$$

Step 4. Set the weights of the estimated characteristics, $W_{i 1}, W_{i 2}, W_{i 3}, W_{i 4}$, and $W_{i 5}$, depending on the importance of every characteristic in the estimated process of the user. In 
this paper, the five weights are set at $0.3,0.15,0.3,0.15$, and 0.1 , which means that the APGC and cost are more important than the other characteristics.

Step 5. Calculate the relation indexes for every rank as follows:

$$
\lambda_{i}=\sum_{j=1}^{5} W_{i j} K_{i j}, \quad i=1,2, \ldots, 5 .
$$

Step 6. Normalize the values of the relation indexes into an interval between -100 and 100 as in (12). This process will be beneficial for the estimated process. Consider

$$
\lambda_{i}^{\prime}= \begin{cases}\frac{\lambda_{i}}{\lambda_{\max }} \times 100, & \lambda_{i}>0, \\ \frac{\lambda_{i}}{\left|\lambda_{\min }\right|} \times 100, & \lambda_{i}<0,\end{cases}
$$

where

$$
\lambda_{\min }=\min \left\{\lambda_{i}\right\} ; \quad \lambda_{\max }=\max \left\{\lambda_{i}\right\} .
$$

Step 7. Rank the normalized correlation indexes to estimate the rank of the tested solar system. Generally, the high correlation index implies that the solar power system has the high probability to belong to this class. Therefore, using the correlation index can be easy to determine the class of system that is most useful for the user and engineer.

\section{Test Results and Discussion}

The paper provides the decision-making method of solar power system that uses the MATLAB software to write the computing program. The testing results of the proposed method are shown in Table 4. It can observe the correlated index of various solar systems with the different rank, it should be noticed that the correlated index is based on the demanded conditions of the user. It can observe the correlated index of various solar power systems from Table 4 . For example, module 1 can be a D-class solar power system due to large correlated index with the $\mathrm{D}$-class, and module 19 is an A-class or better solar power system due to large correlated index with the A-class. On the contrary, the module 25 is an E-class or bad solar power system in the demanded conditions of the user. Table 5 compiles statistics of the top 5 according to $\mathrm{A}$ and $\mathrm{E}$ classes with correlated index the top 5 of the A-class are modules 19, 10, 20, 3, and 7 , respectively, and the top 5 of the E-class include modules $4,25,9,27$, and 30, respectively. Therefore, the proposed EDMM is useful to determine the optimal solar power system based on the predetermined specifications of the user or solar system engineer.

\section{Conclusion}

The paper combines the commercial solar simulated software with the proposed EDMM to determine the optimal solar
TABLE 4: The correlation results of solar modules.

\begin{tabular}{lccccc}
\hline Sample & A & B & D & C & E \\
\hline Module 1 & -40 & -76 & 38 & 14 & -56 \\
Module 2 & -20 & -79 & 10 & 12 & -53 \\
Module 3 & 46 & -52 & 14 & 15 & -80 \\
Module 4 & -100 & -94 & -54 & -85 & 26 \\
Module 5 & -37 & 18 & 3 & 44 & -29 \\
Module 6 & 25 & 9 & -53 & 10 & -68 \\
Module 7 & 37 & 11 & -50 & 24 & -40 \\
Module 8 & -60 & 22 & 100 & -29 & -46 \\
Module 9 & -76 & -62 & 20 & -28 & 9 \\
Module 10 & 62 & 48 & 2 & 36 & -36 \\
Module 11 & -8 & -67 & 8 & -19 & -61 \\
Module 12 & -33 & 10 & 6 & 60 & -31 \\
Module 13 & -17 & -15 & 13 & 37 & -36 \\
Module 14 & 18 & 36 & -53 & 43 & -51 \\
Module 15 & 17 & 50 & -49 & 39 & -53 \\
Module 16 & 1 & 48 & -36 & 12 & -42 \\
Module 17 & -54 & -62 & -57 & 66 & 1 \\
Module 18 & 5 & 24 & -45 & 42 & -46 \\
Module 19 & 66 & -77 & -62 & 7 & -91 \\
Module 20 & 56 & -60 & 19 & 11 & -82 \\
Module 21 & 12 & -64 & -27 & -75 & -72 \\
Module 22 & -39 & 17 & 42 & 2 & -26 \\
Module 23 & -82 & 3 & 26 & -59 & -44 \\
Module 24 & 8 & 42 & -42 & 54 & -49 \\
Module 25 & -53 & -72 & -32 & -27 & 16 \\
Module 26 & 31 & -34 & -58 & 30 & -72 \\
Module 27 & -89 & -80 & 17 & -62 & 3 \\
Module 28 & 20 & 17 & -48 & 33 & -46 \\
Module 29 & -29 & 24 & -38 & 10 & -66 \\
Module 30 & -84 & 4 & -74 & 27 & 2 \\
\hline & & & & &
\end{tabular}

TABLE 5: The top 5 of A-class and E-class.

\begin{tabular}{lcc}
\hline Ranks & A-class & E-class \\
\hline 1st & Module 19 & Module 4 \\
2nd & Module 10 & Module 25 \\
3rd & Module 20 & Module 9 \\
4th & Module 3 & Module 27 \\
5th & Module 7 & Module 30 \\
\hline
\end{tabular}

power system based on the predetermined specifications of the user or the engineer. The calculation of the proposed decision-making algorithm is also fast and very simple. It can be easily implemented by PC software. Test results show that the proposed method cannot only estimate the class of solar system, but it can also be applied to the selecting tools of other related renewable power systems such as wind power and full cells systems. The proposed method is also a new decisionmaking scheme for other engineering problems. 


\section{References}

[1] H. Wang, Y. Li, J. Wang, and Z. Wang, "Analysis of photovoltaic charging system based on MPPT," in Proceedings of the PacificAsia Workshop on Computational Intelligence and Industrial Application (PACIIA '08), pp. 498-501, December 2008.

[2] M. Taherbaneh and K. Faez, "Maximum power point estimation for photovoltaic systems using neural networks," in Proceedings of the IEEE International Conference on Control and Automation ThC4-5 (ICCA '07), pp. 1614-1619, Guangzhou, China, June 2007.

[3] M. Taherbaneh, H. G. Fard, A. H. Rezaie, and S. Karbasian, "Combination of fuzzy-based maximum power point tracker and sun tracker for deployable solar panels in photovoltaic systems," in Proceedings of the IEEE International Conference on Fuzzy Systems (FUZZ '07), July 2007.

[4] M. H. Wang, "A novel extension method for transformer fault diagnosis," IEEE Transactions on Power Delivery, vol. 22, no. 8, pp. 63-64, 2002.

[5] M. H. Wang, "Application of extension theory to vibration fault diagnosis of generator sets," IEE Proceedings, vol. 151, no. 4, pp. 503-508, 2004.

[6] W. Cai, "Extension managementengineering and applications," International Journal of Operations and Quantitative Management. In press.

[7] M. H. Wang and C. P. Hung, "Extension neural network and its applications," Neural Networks, vol. 16, no. 5-6, pp. 779-784, 2003.

[8] M. H. Wang, Y. F. Tseng, H. C. Chen, and K. H. Chao, "A novel clustering algorithm based on the extension theory and genetic algorithm," Expert Systems with Applications, vol. 36, no. 4, pp. 8269-8276, 2009. 

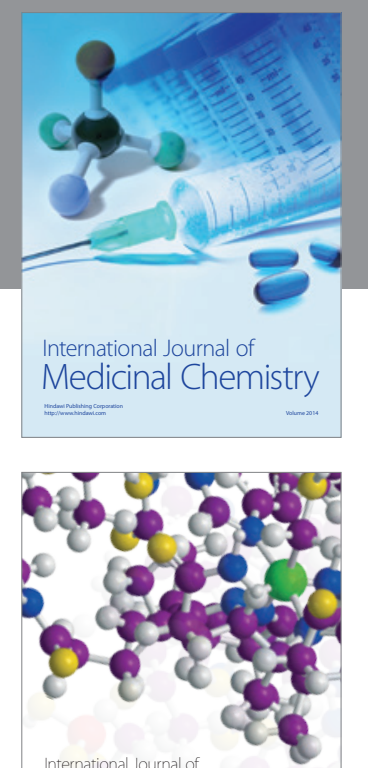

\section{Carbohydrate} Chemistry

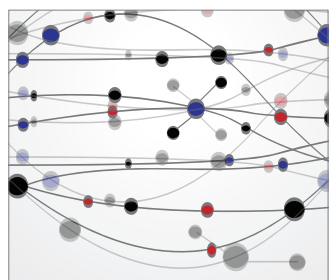

The Scientific World Journal
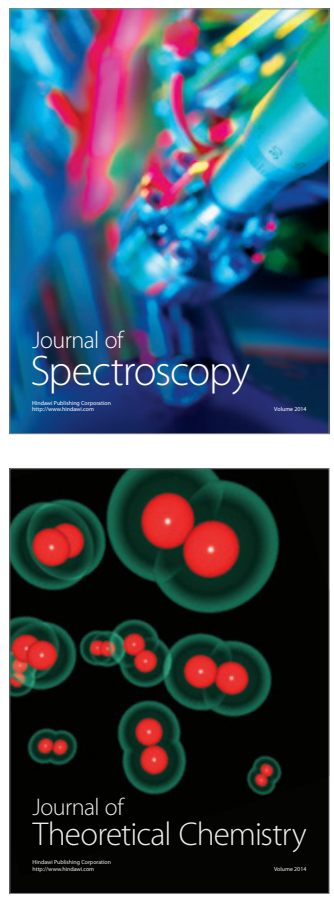
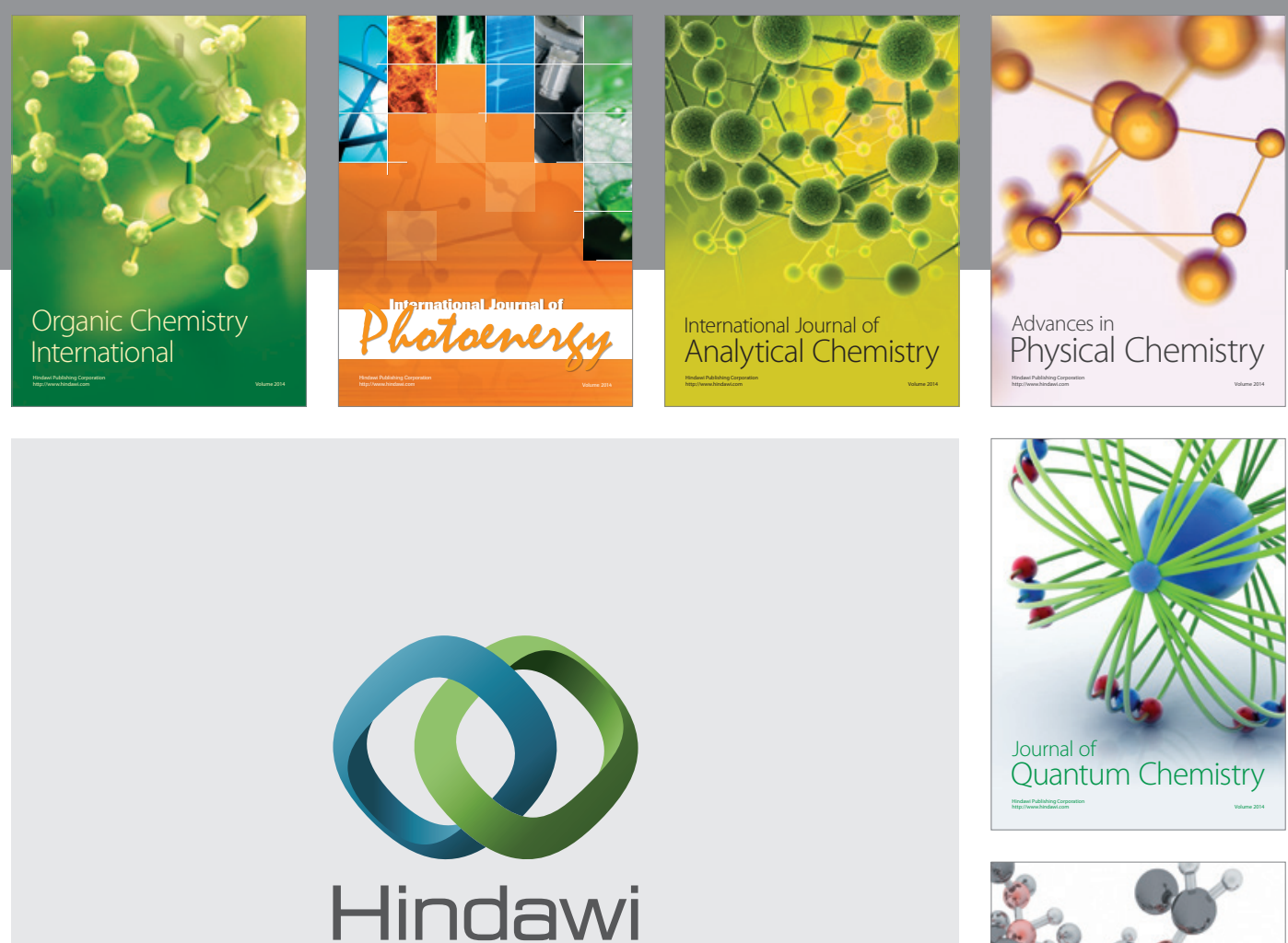

Submit your manuscripts at

http://www.hindawi.com

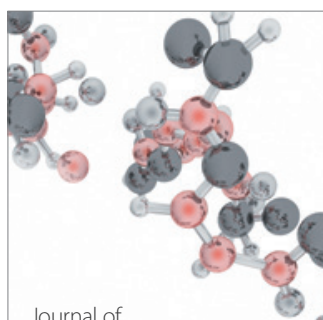

Analytical Methods

in Chemistry

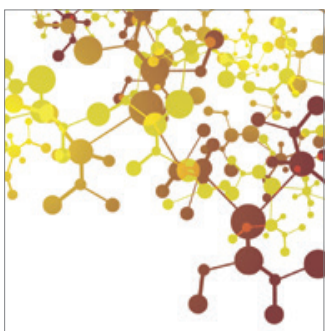

Journal of

Applied Chemistry

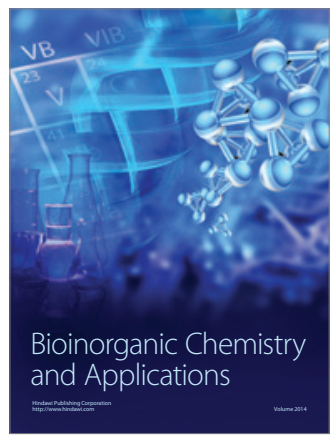

Inorganic Chemistry
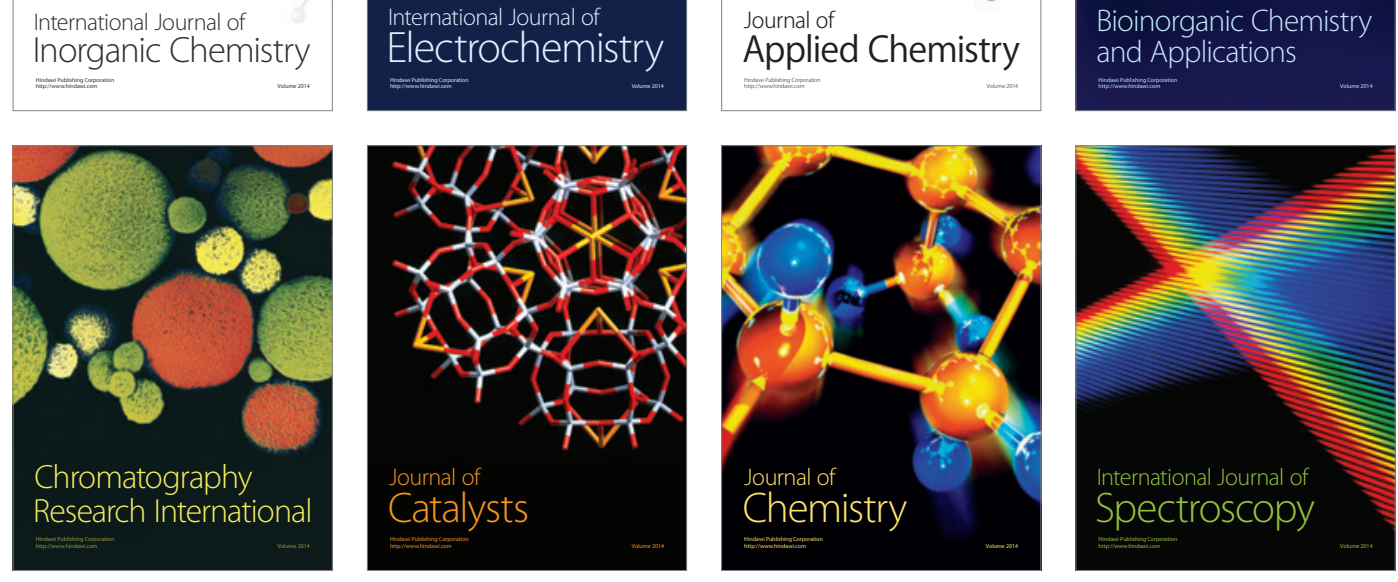